\title{
Co-occurrence of communication disorder and psychiatric disorders in maltreated children and adolescents: relationship with global functioning
}

\author{
Luciene Stivanin, ${ }^{1}$ Christian C. de Oliveira, ${ }^{1}$ Fernanda P. dos Santos, ${ }^{1}$ Bernardo dos Santos, ${ }^{2}$ \\ Sandra Scivoletto ${ }^{1}$ \\ ${ }^{1}$ Departamento e Instituto de Psiquiatria, Faculdade de Medicina, Universidade de São Paulo (USP), São Paulo, SP, Brazil. \\ ${ }^{2}$ Instituto de Matemática e Estatística, USP, São Paulo, SP, Brazil.
}

\begin{abstract}
Objective: To study the co-occurrence of psychiatric disorders (PD) and communication disorders (CD) and their relationship with global functioning in maltreated children and adolescents.

Methods: The sample comprised 143 maltreated children and adolescents (55.8\% male). All underwent clinical communication and psychiatric evaluations, as well as global functioning assessment using the Children's Global Assessment Scale (C-GAS).

Results: Four groups emerged from evaluation: Group $1(n=7,4.9 \%)$ did not exhibit any disorders; Group $2(n=26,18.2 \%)$ exhibited PD; Group $3(n=34,23.8 \%)$ exhibited CD; and Group $4(n=76$, $53.1 \%)$ exhibited both PD and CD on evaluation. Significant differences in global functioning scores were found between $\mathrm{G} 1$ and $\mathrm{G} 2, \mathrm{G} 1$ and $\mathrm{G} 4, \mathrm{G} 2$ and $\mathrm{G} 4$, and $\mathrm{G} 3$ and $\mathrm{G} 4$, with the highest C-GAS scores found in $\mathrm{G} 1$ and the lowest in $\mathrm{G} 4$.

Conclusion: Rates of PD and CD are high in this maltreated population. The presence of PD has a major impact on C-GAS score, and the simultaneous presence of CD increases the already impaired function of PD. Demonstration of the additive effects of PD and CD on youth functioning suggests that professionals should be alert to the presence of both disorders to better act preventively and therapeutically in a high-risk population.
\end{abstract}

Keywords: Attention-deficit hyperactivity disorder; stress; child psychiatry; language; violence/ aggression

\section{Introduction}

Child maltreatment, also referred to as child abuse and neglect, includes all forms of physical, emotional, and sexual abuse, neglect, and exploitation that result in actual or potential harm to the child's health, development, or dignity. ${ }^{1}$ It is estimated that, each year, one in 15 people under 18 years of age is a victim of abuse and neglect worldwide, totaling approximately 150 million individuals. ${ }^{2}$ Child maltreatment is a major public health problem that poses significant barriers to healthy development across contexts. ${ }^{3}$ It is also an important predictor of crime and violence in adulthood. ${ }^{4}$

Many individuals exposed to intense stressors, including childhood maltreatment, prosper and succeed despite these adversities. ${ }^{4}$ Others may show several problems as a result of exposure to maltreatment: externalizing and internalizing problems, ${ }^{5-8}$ lower intellectual functioning, ${ }^{8}$ poor academic achievement, ${ }^{9,10}$ and communication disorders (CD). ${ }^{11-13}$ Following exposure to traumatic stress,

Correspondence: Luciene Stivanin, Departamento de Psiquiatria, Faculdade de Medicina, USP, Rua Dr. Ovídio Pires de Campos, 785, CEP 05403-010, São Paulo, SP, Brazil.

E-mail: stivanin @usp.br

Submitted Sep 25 2014, accepted Jan 212015. individuals are primed to misperceive threat and present overly emotional and ineffective cognitive responsiveness, as well as disorganized or maladaptive behavioral responses to perceived threats. ${ }^{6}$ Child maltreatment is associated with language delay in both vocabulary and production of syntactic structures, ${ }^{11}$ in auditory and expressive communication. ${ }^{13}$

Speech, language, and communication underpin everything we do - making our needs known, expressing our likes and dislikes, interacting with others, and building relationships. Language is a complex system used to represent thoughts and ideas. Speech is the verbal means of communicating, and consists of the following aspects: articulation (how speech sounds are made), voice (use of the vocal folds and breathing to produce sound), and fluency (the rhythm of speech). ${ }^{14}$

Early language skills are strong predictors of a child's emergent literacy, reading skills, and long-term academic success. Problems in developing language skills cause disorders in learning, as well as social, emotional, and behavioral issues. ${ }^{15-17}$ Difficulties in social adjustment increase the risk of psychiatric problems in adulthood. ${ }^{18}$

In the normal course of development, language is intertwined with abilities in the cognitive, social, and emotional domains (and vice versa). Language helps children organize their perceptions, sharpen their memories, 
and learn about their world. Language is not only a tool for thought and social interaction, but also a means to control one's behavior and emotions and those of others. More specifically, language plays a role in enabling children to understand, encode, organize, and retrieve rules that contribute to emotional and behavioral regulation. As language develops, children begin to discuss their emotions with their caregivers and, in turn, their caregivers help them deal constructively with negative emotions by talking about them. These supportive conversations facilitate children's capacity to devise their own strategies to regulate their emotions. Moreover, children who do not learn how to regulate emotions are likely to alienate adults and peers when they act out their anger or frustrations physically rather than use language to communicate in a more appropriate way. ${ }^{19}$

The brain regions involved in language processing can mediate executive skills which are important to the regulation of aggressive impulses, such as cognitive modulation of emotions and restraint of aggressiveness; abnormalities in these regions may lead to changes in the perception of external stimuli and trigger violent behaviors. ${ }^{16}$

Beyond language, others communication deficits could also adversely affect the development of social problemsolving skills, leading to an increased risk for development of mental disorders. Although the literature points to the importance of communication for psychosocial development and to the relationship between $C D$ and psychiatric disorders (PD), there are no studies about the association of these disorders and their impact on the global functioning of the individual in maltreated children and adolescents.

This study proposes to examine the co-occurrence of PD and CD, as well as their relationship with global functioning, in maltreated children and adolescents. We set out to answer the following research questions: What is the prevalence of $P D$ and $C D$, isolated and concomitant, in maltreated children? Is there an association between type of $P D$ and $C D$ ? Is the global functioning of maltreated children and adolescents worse when PD and/or CD are present?

Based on literature about mistreatment in childhood, our hypotheses were that the population of this study would present with a high percentage of both psychiatric disorders and $C D$ and that there would be a strong association between such disorders and lower global functioning. Speech and language difficulties do not always affect communication, because the child can develop strategies that meet such deficiency. However, we believe that, in victims of abuse, these problems may affect communicative effectiveness, due to a higher prevalence of PD as well as greater social inability.

\section{Methods}

\section{Sample}

This cross-sectional study was approved by the Research Ethics Committee of Universidade de São Paulo (USP) School of Medicine, São Paulo, Brazil, with protocol number 1018-/-09. The sample comprised victimized children and adolescents who, from July 2009 to July 2011, were referred to a multidisciplinary community health center (Programa Equilíbrio) specialized in outpatient treatment of children and adolescents with histories of maltreatment and social deprivation. The center offers the following services: psychiatry, psychotherapy, neuropsychology, speech therapy, educational psychology, physiotherapy, occupational therapy, social work, sports activities, and art education. Children and adolescents are referred to this service either by shelter staff or by the Child and Juvenile Court. ${ }^{20}$

The legal guardians of the children were informed about the conditions of the study and signed the document freely. Patients were included according to the following criteria: a) living in a socially vulnerable, high-risk situation, as determined either clinically or by child protective services (one or more social diagnoses according to chapter $Z$ of the ICD-10 ${ }^{21}$ - physical and/or sexual violence, family neglect, and/or adverse socioeconomic condition); b) no longer living in the streets (i.e., living in a group shelter, with their original family, or with a foster family); and c) agreement to participate in the study by provision of written informed consent. Exclusion criteria included: a) children or adolescents from locations other than São Paulo; b) age greater than 19 years at first assessment; c) refusal of all healthcare assessments or services; and d) those who presented with acute psychiatric symptoms and those who had previously undergone speech therapy.

\section{Instrument and procedures}

Psychiatric diagnoses were assessed using the Schedule for Affective Disorders and Schizophrenia for School-Age Children (K-SADS-PL), a semi-structured diagnostic interview $^{22}$ to assess current and past episodes of psychopathology in children and adolescents based on the DSM-IV criteria. The Brazilian version of the K-SADS$\mathrm{PL}$ (in Portuguese) was developed by Brasil and Bordin from the original English version. ${ }^{23}$ To facilitate statistical analysis, diagnoses were clustered into 13 categories based on the ICD-10, namely: substance use (F10-F19); schizophrenia and schizoaffective disorder (F20, F25); other psychotic disorder (F21-F24 and F26-F29); bipolar disorder (F30, F31); depressive disorders (F32-39); anxiety disorders (F40-F48); eating disorders (F50); habit and impulse disorders (F63); mental retardation (F70F79); disorders of psychological development (F80-F89); attention-deficit hyperactivity disorder (ADHD) (F90); conduct disorder (F91); and a category reflecting other disorders of early childhood (F92-F99).

Assessment of communication by speech-language pathologists was performed with validated instruments for Brazil in the following areas: ABFW - phonology, vocabulary, and pragmatic fluency ${ }^{24}$; oral discourse ${ }^{25}$; reading and writing skills ${ }^{26}$; and articulation. ${ }^{27}$ After the evaluation, the absence or presence of $C D$ was determined. $C D$ were classified as language disorder (phonological disorder, receptive-expressive language disorder, semantic-syntactic disorder, written language disorder), speech disorder (speech articulation disorder, disfluency), or pragmatic skills disorder. 
Table 1 Age and gender distribution of participants according to presence and/or absence of communication and psychiatric disorders $(n=143)$

\begin{tabular}{lcccc}
\hline Group & $\mathrm{n}$ & Age & Males & Females \\
\hline G1 - Absence of CD/absence of PD & 7 & $10.0 \pm 3.0$ & $1(14.3)$ & $6(85.7)$ \\
G2 - Absence of CD/presence of PD & 26 & $11.3 \pm 3.2$ & $14(53.8)$ & $12(46.2)$ \\
G3 - Presence of CD/absence of PD & 34 & $9.2 \pm 3.0$ & $13(38.2)$ & $21(61.8)$ \\
G4 - Presence of CD/presence of PD & 76 & $10.3 \pm 2.8$ & $79.1)$ & $25(32.9)$ \\
Total & 143 & $10.2 \pm 3.0$ & $79(55.2)$ & $64(44.8)$ \\
\hline
\end{tabular}

Data presented as mean \pm standard deviation or $n(\%)$, unless otherwise stated.

$\mathrm{CD}=$ communication disorder; $\mathrm{PD}=$ psychiatric disorder.

The Children's Global Assessment Scale (C-GAS) was used to assess global functioning. C-GAS scores were rated by the professional who had been in contact with the child for the longest duration and had access to all of their follow-up information. The C-GAS provides a good estimate of overall severity of disturbance (range, 0-100). Scores over 90 indicate superior functioning, whereas scores under 70 indicate impaired global functioning. ${ }^{28}$ This instrument has not been validated for use in Brazil, but is widely used for research purposes in the country. ${ }^{29,30}$

\section{Statistical analysis}

Descriptive analyses of percent prevalence of PD and $C D$, global functioning, and gender, as well as comparisons of these variables between the four subgroups of subjects, are reported. After evaluation, four groups were established: G1 - absence of CD and PD; G2 - absence of CD and presence of PD; G3 - presence of CD and absence of PD; and G4 - presence of both CD and PD. Comparison of categorical variables among groups was performed using a likelihood ratio test for contingency tables, and continuous variables were tested with a oneway ANOVA model. The type I error rate was set at $5 \%$. All tests were two-tailed and all analyses were conducted in the SPSS version 14 environment.

\section{Results}

From July 2009 to July 2011, 216 patients were admitted for follow-up in the program. Of these, all had experienced maltreatment, but only $143(66.2 \%)$ met the inclusion criteria and had complete speech assessment results available. Overall, the mean age was 10.2 years (SD 2.5); $55.8 \%$ of participants were male (mean age 10.3 years, SD 2.5) and $44.2 \%$ were female (mean age 9.9 years, SD 2.6). The average number of social diagnoses by subject was 6.8. Briefly, the percentage of subjects affected by the most frequent social diagnoses was as follows: problems related to housing and economic circumstances (Z59), 100\%; removal from their homes during childhood (Z61.1), 87\%; institutional upbringing (Z62.2), 53.4\%; inadequate parental supervision and control (Z62.0), 47.3\%; emotional neglect of child (Z62.4), 47.3\%; family history of alcohol abuse (Z81.1), 37\%; alleged physical abuse of child (Z61.6), 36.3\%; alleged sexual abuse (Z61.4, Z61.5), 30.8\%; other psychoactive substance abuse in the family history (Z81.3), $22.6 \%$.
After evaluation, seven participants (4.9\%) were not diagnosed with any CD or PD, and were thus allocated to G1; 26 (18.2\%) presented with only PD, and were thus placed in G2; 34 (23.8\%) presented with only CD and were placed in G3; and 76 (53.1\%) presented with both PD and CD, and thus composed G4. The distribution of the subjects by presence of disorders, age, and gender is shown in Table 1 . The majority of the sample $(53.1 \%)$ presented with both active PD and CD. There were no significant differences in age across groups $(p=0.072)$. The proportion of boys was highest in G3 (67.1\%) and lowest in G1 (14.3\%). These differences in gender distribution were statistically significant $(p=0.004)$.

The types of PD and CD and their distributions are shown in Figures 1 and 2 respectively.

The distribution of CD within each PD category is shown in Figure 3. When examining each category of $P D$ for association with specific CD, statistically significant associations were noted between mental retardation and receptive language disorder $(p<0.001)$ and between hyperkinetic disorder and pragmatic skills disorder $(p=0.035)$.

The C-GAS scores of each group are shown in Table 2. The global functioning scores of participants without any disorders (G1) ranged between 61 and 70, a belowaverage range characterized by the presence of some problems in only one area or minor difficulties. Significant differences in C-GAS scores were found between G1 and $\mathrm{G} 2$ ( $p=0.005), \mathrm{G} 1$ and $\mathrm{G} 4(\mathrm{p}=0.000), \mathrm{G} 2$ and $\mathrm{G} 4$ $(p=0.000)$, and $G 3$ and $G 4(p=0.000)$. On average, there

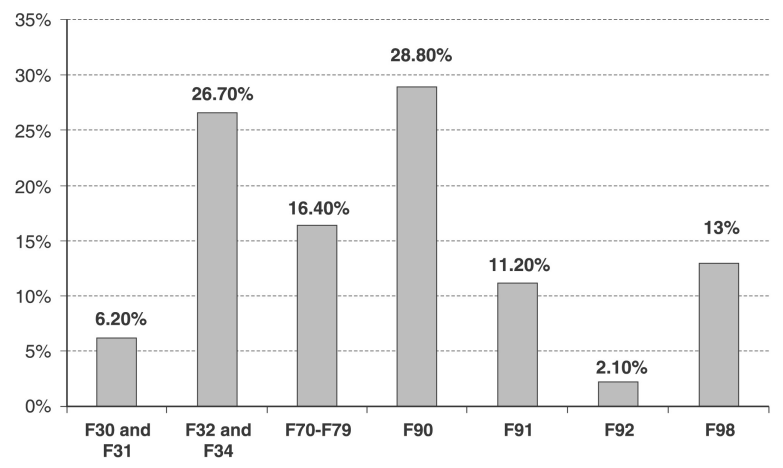

Figure 1 Frequency of psychiatric disorders in maltreated children and adolescents. F30 and F31 = bipolar disorder; $\mathrm{F} 32$ and $\mathrm{F} 34$ = depressive disorders; $\mathrm{F} 70-79=$ mental retardation; $\mathrm{F} 90$ = attention-deficit hyperactivity disorder (ADHD); F91 = conduct disorder; F92 and F98 = other disorders of early childhood. 


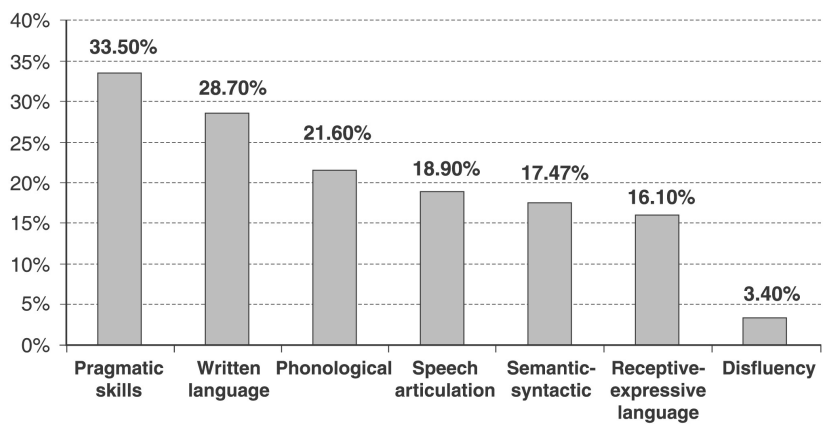

Figure 2 Frequency of communication disorders in maltreated children and adolescents $(n=143)$.

was a 12-point reduction in global functioning when the individual presented with a PD (G2) (significant, $p=0.005$ ) or $C D(G 3)$ (significant, $p=0.041$ ), placing these groups in a range between 51 and 60 , characterized by problems in more than one area. When PD and CD co-occurred (G4), the reduction in global functioning was greater (an average of 23.6 points), with participants scoring in the 41-50 range, considered indicative of obvious problems, deficits in most areas, or severe deficits in one area.

\section{Discussion}

This study aimed to investigate how comorbid PD and $C D$ are related to the global functioning of maltreated children. The results showed high percentages of both $C D$ and $P D$ in this population.

Rates of PD similar to that found in our study $(71.3 \%)$ have also been demonstrated in previous studies of maltreated children in Brazil (78.7 to $88.8 \%$ ), confirming a relationship between early emotional stress and PD in a population exposed to maltreatment. ${ }^{7,8}$

The percentage of $C D$ in this study was higher than that found in the general population (2.3 to $24.6 \%){ }^{31}$ However, no prior studies of CD (including language disorders, speech disorders, and pragmatic skill disorders) have been conducted in similar populations in our country. In the literature, authors have mainly studied language disorders. Eigsti \& Cicchetti compared maltreated children and non-maltreated controls and identified difficulties in vocabulary and syntactical structures production in maltreated children at 60 months. ${ }^{11}$ Stacks et al. studied language development in children aged 4, 8, 24, 39 and 70 months; their sample included children living with biological parents, in shelters, and with other caregivers, and the authors found lower language functioning (comprehension and expression) scores at all stages, with decline close to age 2 years and improvement to age 5 years (start of preschool) in all groups. ${ }^{12}$ However, the age of the participants was different from that of our sample, the authors focused solely on language functioning, and the study did not analyze the relationship between PD and $\mathrm{CD}$.

Early emotional stress may cause alterations in the brain and in the psychobiological processes that affect neurodevelopmental functions, including language. ${ }^{32,33}$ Additionally, the presence of sociodemographic risk factors, such as violent family environments and lowquality relationships between caregivers and children, interferes with normal development. For example, the type and quality of linguistic stimuli provided to the child during development affects language acquisition, and mothers who are depressed, as well as those who maltreat their children, are less communicative and address their children with lower frequency. ${ }^{12,13}$

In our sample, we found an association between PD and CD: $74.5 \%$ of children with a psychiatric diagnosis also had CD. These rates are higher than those found in the literature about the association between communication difficulties and emotional and behavioral problems: in prior studies, 30 to $50 \%$ of children with CD have been reported to exhibit behavior disorder. ${ }^{34}$ In another study, children aged 30 months with behavioral and emotional difficulties presented with a threefold rate of language problems, and 60.6 to $63.1 \%$ of children with speech delay had a higher occurrence of emotional and behavioral

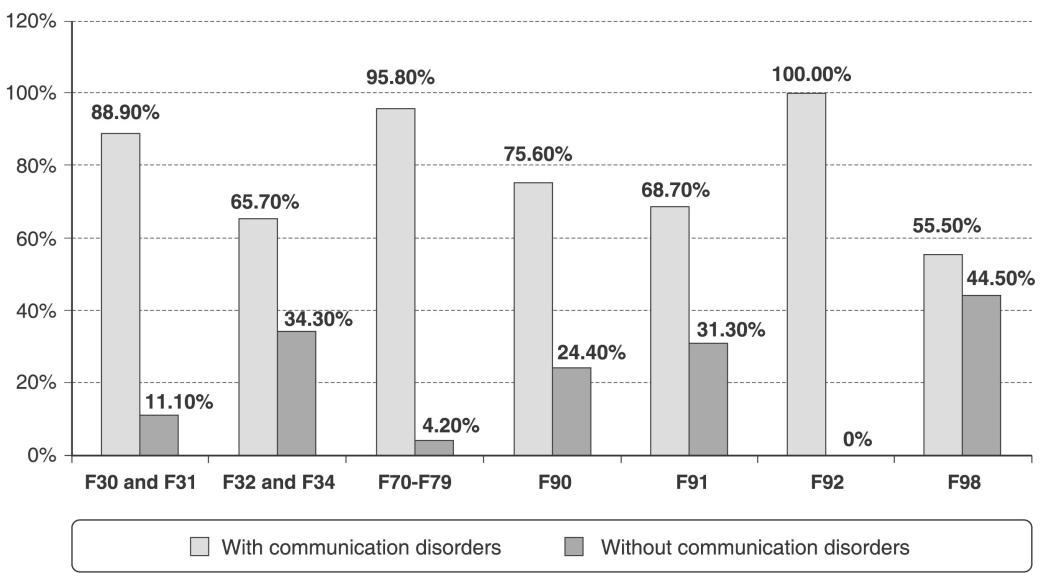

Figure 3 Frequency of communication disorders in maltreated children and adolescents with different psychiatric disorders. F30 and F31 = bipolar disorder; F32 and F34 = depressive disorders; F70-79 = mental retardation; F90 = attention-deficit hyperactivity disorder (ADHD); F91 = conduct disorder; F92 and F98 = other disorders of early childhood. 
Table 2 Children's Global Assessment Scale (C-GAS) scores of participants according to presence and/or absence of communication and psychiatric disorders $(n=143)$

\begin{tabular}{lc}
\hline Participants & C-GAS T0 \\
\hline G1 - Absence of PD/absence of CD $(n=7)$ & $68.8 \pm 9.6$ \\
G2 - Absence of CD/presence of PD $(n=26)$ & $56.9 \pm 13.7$ \\
G3 - Absence of PD/presence of CD $(n=34)$ & $55.5 \pm 10.2$ \\
G4 - Presence of PD/presence of CD $(n=76)$ & $45.2 \pm 11.8$ \\
Total & $51.0 \pm 13.6$
\end{tabular}

Data presented as mean \pm standard deviation.

T0 = first assessment; CD = communication disorder; C-GAS =

Children's Global Assessment Scale; PD = psychiatric disorder.

problems. ${ }^{35}$ Therefore, when considering specific psychiatric conditions, other rates of $C D$ may be found.

None of these studies analyzed the co-occurrence of PD and CD in maltreated children. Neurodevelopmental research shows that school-aged adopted children with a history of severe maltreatment can have very complex and sometimes disabling neuropsychiatric problems and/ or language delay, but there has been no study of association between both types of disorders. ${ }^{36}$

The process whereby language regulates behavior begins during childhood: children use speech to plan tasks, regulate their emotions, and guide their thoughts. Due to deficits in any of these speech-influenced developmental activities, children with $C D$ may have difficulty dealing with stressors. This may explain the higher relationship between PD and CD observed in the present study.

The receptive-expressive language disorder, characterized by difficulties in language comprehension, elaboration, and expression, was prominent in children who presented with mental retardation. This finding was expected, given the cognitive impairment found in this group. The intellectual reduction found in maltreated children is characterized by a higher reduction in language skills than in visual-spatial ones. $^{8}$

Children with ADHD, the most common condition in this study, have been shown to have alterations in auditory processing, ${ }^{37}$ working memory, semantic abilities, identification of letters and sounds, reading of words and pseudowords, syntactic processes, and comprehension. ${ }^{38}$ In this study, even though participants with ADHD exhibited disorders of oral and written language and speech, the only statistically significant association was with pragmatic disorders, suggesting that the social use of language more than the linguistic structure itself is related to the behaviors of agitation, impulsivity, and inattention.

The significant difference in the proportion of boys and girls in the groups without disorders (higher percentage of girls) and in the group with concomitant PD and CD (higher percentage of boys) is consistent with the greater susceptibility of boys to development of mental disease and CD. ${ }^{39}$

Another important finding was the significant association between PD and CD and the global functioning of the participants. The simultaneous presence of communication and behavioral/emotional problems correlates with worsened psychological, occupational, and social functioning in most environments and activities.

At school, maltreated children show less academic engagement. ${ }^{40}$ Problematic behaviors, both internalizing and externalizing, may compromise adaptation to school in situations such as posing questions, solving doubts, and asking classmates and teachers for help. ${ }^{41}$ Similarly, the lower the degree of intelligibility of the child's speech (as in CD), the greater the difficulty in interpersonal relationships and in adapting to the school environment. However, we found no prior studies that analyzed the cooccurrence of $\mathrm{PD}$ and $\mathrm{CD}$ and its consequences on global functioning.

This study has many implications. First, it demonstrates the need for public policies devoted to supporting this population, due to high rates of PD and CD. Development of communication, regulation of behavior, and emotional stability are vital to the acquisition of social abilities in childhood that affect social outcomes as adults. If highrisk children are left unsupported, interpersonal difficulties, school failure, and lack of guidance may drive them toward drug use, illicit activities, and violence as means of solving interpersonal problems, whether at home, at school, or on the street.

Second, the association between PD and CD has implications for treatment planning. Speech-language pathologists have a critical role to play in the treatment of this population, in order to provide patients with the adequate development of communication skills necessary to overcome daily challenges, facilitate interpersonal relationships, engage in school, and other areas of global functioning. The speech-language pathologist must also involve the caregivers so that they may offer support and adequate linguistic stimuli.

Third, early and systematic intervention may alter the life trajectory of this high-risk population, and the speechlanguage pathologist is indispensable in this process. Programs focusing on decreasing school violence use stimulation and training of social abilities through language-based activities. For example, authors have used social stories to decrease the number of aggressive behaviors in preschoolers. These stories are short narratives, used over a 4-week period, which have been demonstrated to produce improvements in social abilities and adaptive behavior, as measured by the BASC-2 scale. ${ }^{40}$ Another study found that, after training, victims and witnesses of violence at school increased the quantity of adequate verbalizations in order to solve a conflict. ${ }^{42}$

Speech-language pathologists may be essential in adapting such programs for use with children with $C D$. Additional efforts at school directed toward high-risk children with $C D$ are essential, given that school engagement is related to reduced crime and violence in early adulthood.

Our initial hypotheses were confirmed by this study. The results showed a relationship among maltreatment, PD, CD, and worsened psychological, social, and occupational functioning.

However, there are important limitations. First, we cannot establish direct causal relations among the studied factors. Second, this population is exposed to other risks, such as limited parental stimulation and maternal diseases during pregnancy, which are risk factors associated with mental disease as well as with disorders of communication and global functioning. Third, we had limited information and precision about the development 
of the participants prior to institutionalization. Further studies should include measurements of neuropsychological function and social abilities, in order to analyze which factors mediate behavior, communication, and global functioning.

Despite these limitations, the importance of communication competence for at-risk children has been established. Language provides the main method of establishing and maintaining social relationships, constitutes a principal means of organizing behavior, and is central to the successful acquisition of many cognitive and academic skills, particularly literacy. It is clear that language acquisition is an integral component in the development of an individual and that failure of the language system can have effects on social, academic, and vocational success which will not lessen over time if left unmanaged. In conclusion, the relationship between PD, CD, and global functioning highlights the need for development of specific public policies aimed at the mental health care of this population.

\section{Acknowledgements}

SS receives research support from Fundação Faculdade de Medicina (FFM), Conselho Nacional de Desenvolvimento Científico e Tecnológico (CNPq), Fundo Municipal dos Direitos da Criança e do Adolescente (FUMCAD), and Fundação de Amparo à Pesquisa do Estado de São Paulo (FAPESP).

\section{Disclosure}

SS has received research and education support from Laboratório Cristália, Novartis, Janssen-Cilag Brasil, and Eli Lilly do Brasil; and has received speaker's honoraria from Instituto Américo Bairral, Colégio Santo Américo, and GSK. The other authors report no conflicts of interest.

\section{References}

1 World Health Organization (WHO). Health topics. Child maltreatment [Internet]. [cited 2008 May 8]. http://www.who.int/topics/child_abuse/en/

2 Svevo-Cianci KA, Hart SN, Rubinson C. Protecting children from violence and maltreatment: a qualitative comparative analysis assessing the implementation of U.N. CRC Article 19. Child Abuse Negl. 2010;34:45-56.

3 Gilbert R, Widom CS, Browne K, Fergusson D, Elspeth W, Janson S. Burden and consequences of child maltreatment in high-income countries. Lancet. 2009;373:68-81.

4 Smith CA, Park A, Ireland TO, Elwyn L, Terence LP. Long-term outcomes of young adults exposed to maltreatment: the role of educational experiences in promoting resilience to crime and violence in early adulthood. J Interpers Violence. 2013;28:121-56.

5 Terr LC. Childhood traumas: an outline and overview. J Lifelong Learn Psychiatry. 2013;1:323-33.

6 Wilson KR, Hansen DJ, Li M. The traumatic stress response in child maltreatment and resultant neuropsychological effects. Aggress Violent Behav. 2011;16:87-97.

7 Silva TF, Cunha PJ, Scivoletto S. High rates of psychiatric disorders in a sample of Brazilian children and adolescents living under social vulnerability urgent public policies implications. Rev Bras Psiquiatr. 2010;32:195-6.

8 de Oliveira PA, Scarpari GK, Dos Santos B, Scivoletto S. Intellectual deficits in Brazilian victimized children and adolescents: a psychosocial problem? Child Abuse Negl. 2012;36:608-10.
9 Leiter J. School performance trajectories after the advent of reported maltreatment. Child Youth Serv Rev. 2007;29:363-82.

10 Perlman SM, Fantuzzo JW. Timing and influence of early experiences of child maltreatment and homelessness on children's educational well-being. Child Youth Serv Rev. 2010;32:874-83.

11 Eigsti IM, Cicchetti D. The impact of child maltreatment on expressive syntax at 60 months. Dev Sci. 2004;7:88-102.

12 Stacks AM, Beeghly M, Partridge T, Dexter C. Effects of placement type on the language developmental trajectories of maltreated children from infancy to early childhood. Child Maltreat. 2010;16:287-99.

13 Stivanin L, Oliveira CCC, Scivoletto S. Levantamento preliminar de patologias na comunicação oral em crianças e adolescentes em situação de vulnerabilidade social. In: $16^{\circ}$ Congresso Brasileiro de Fonoaudiologia; 2008; Campos do Jordão, SP. Anais do congresso em CDR.

14 Bowen C. Communication disorders glossary [Internet]. 2014 Feb 06 [cited 2015 Feb 26]. http://www.speech-language-therapy.com/index. php?option=com_content\&view=article\&id=14\&ltemid $=123$

15 McConnellogue S. Educational psychology in practice: theory, research and practice in educational psychology. Educ Psychol Prac. 2011;27: 53-64.

16 Miller LA, Collins RL, Kent TA. Language and the modulation of impulsive aggression. J Neuropsychiatry Clin Neurosci. 2008;20: 261-73.

17 Kreisman NV, John AB, Kreisman BM, Hall JW, Crandell CC. Psychosocial status of children with auditory processing disorder. J Am Acad Audiol. 2012;23:222-33.

18 Clegg J, Hollis C, Mawhood L, Rutter M. Developmental language disorders - a follow-up in later adult life. Cognitive and psychosocial outcomes. J Child Psychol Psychiatry. 2005;46:128-49.

19 Bolter NA, Cohen NJ. Language impairment and psychiatric comorbidities. Pediatr Clin North Am. 2007;54:525-42, vii.

20 Scivoletto S, da Silva TF, Rosenheck RA. Child psychiatry takes to the streets: A developmental partnership between a university institute and children and adolescents from the streets of Sao Paulo, Brazil. Child Abuse Negl. 2011;35:89-95.

21 Organização Mundial da Saúde. Classificação Internacional das Doenças (CID-10). 10a revisão. Porto Alegre: Artes Médicas; 1992.

22 Kaufman J, Birmaher B, Brent D, Rao U, Flynn C, Moreci P, et al. Schedule for Affective Disorders and Schizophrenia for School-Age Children-Present and Lifetime Version (K-SADS-PL): initial reliability and validity data. J Am Acad Child Adolesc Psychiat. 1997;36:980-8.

23 Brasil HH, Bordin IA. Convergent validity of K-SADS-PL by comparison with $\mathrm{CBCL}$ in a Portuguese speaking outpatient population. BMC Psychiatry. 2010;19:10-83.

24 Andrade CRF, Béfi-Lopes DM, Fernandes FDM, Wertzner H. ABFW teste de linguagem infantil nas áreas de fonologia, vocabulário, fluência e pragmática. Carapicuiba: Pró-Fono; 2000.

25 Norbury CF, Bishop DV. Narrative skills of children with communication impairments. Int J Lang Commun Dis. 2003;38:287-313.

26 Salles JF, Parente MAMP. Relação entre os processos cognitivos envolvidos na leitura de palavras e as habilidades de consciência fonológica em escolares. Pró-Fono Rev Atual Cient. 2002;14:175-86.

27 Behalu M, Pontes P. Avaliação e tratamento das disfonias. São Paulo: Lovise; 1995.

28 Shaffer D, Gould MS, Brasic J, Ambrosini P, Fisher P, Bird H, et al. A children's Global Assessment Scale (CGAS). Arch Gen Psychiatry. 1983;40:1228-31.

29 Duarte CS, Bordin IAS. Instrumentos de avaliação. Rev Bras Psiquiatr. 2000;22:55-8

30 Stefanovics EA, Filho MV, Rosenheck RA, Scivoletto S. Functional outcomes of maltreated children and adolescents in a communitybased rehabilitation program in Brazil: Six-month improvement and baseline predictors. Child Abuse Negl. 2014;38:1231-7.

31 Law J, Boyle J, Harris F, Harkness A, Nye C. The feasibility of universal screening for primary speech and language delay: findings from a systematic review of the literature. Dev Med Child Neuroci. 2008:42:190-200.

32 Teicher MH, Dumont NL, Ito Y, Vaituzis C, Giedd JN, Andersen SL. Childhood neglect is associated with reduced corpus callosum area. Biol Psychiatry. 2004;56:80-5.

33 Twardosz S, Lutzker JR. Child maltreatment and the developing brain: a review of neuroscience perspectives. Aggress Violent Behav. 2010;15:59-68. 
34 Plomim R, Price TS, Eley TC, Dale PS, Stevenson J. Associations between behaviour problems and verbal and nonverbal abilities and disabilities in early childhood. J Child Psychol Psychiatry. 2002;43: 619-33.

35 Sim F, O'Dowd J, Thompson L, Law J, Macmillan S, Affleck M, et al. Language and social/emotional problems identified at a universal developmental assessment at 30 months. BMC Pediatr. 2013;13:206.

36 Kočovská E, Puckering C, Follan M, Smillie M, Gorski C, Barnes J, et al. Neurodevelopmental problems in maltreated children referred with indiscriminate friendliness. Res Dev Disabil. 2012;33:1560-5.

37 Abdo AGR, Murphy CFB, Schochat E. Habilidades auditivas em crianças com dislexia e transtorno do déficit de atenção e hiperatividade. Pró-Fono Rev Atual Cient. 2010;22:25-30.

38 Capellini SA, Ferreira TL, Salgado CA, Ciasca SM. Desempenho de escolares bons leitores, com dislexia e com transtorno do déficit de atenção e hiperatividade em nomeação automática rápida. Rev Soc Bras Fonoaudiol. 2007;12:114-9.

39 Stanton-Chapman TL, Chapman DA, Bainbridge NL, Scott KG. Identification of early risk factors for language impairment. Res Dev Disabil 2002;23:390-405.

40 Shonk SM, Cicchetti D. Maltreatment, competency deficits, and risk for academic and behavioral maladjustment. Dev Psychol. 2001;37: 3-17.

41 Pereira Del Prette ZA, da Rocha MM, de Matos Silvares EF, Del Prette A. Social skills and psychological disorders: converging and criterion-related validity for YSR and IHSA-Del-Prette in adolescents at risk. Univ Psychol. 2012;11:941-55.

42 Benish TM, Bramlett RK. Using social stories to decrease aggression and increase positive peer interactions in normally developing preschool children. Educ Psychol. 2011;27:11-7. 